\title{
The future of failure to warn in dentistry after Montgomery: reflections from Australia
}

\author{
A. C. L. Holden'
}

\section{In brief}

Illustrates how the law of consent in the UK may develop in the same way as Australia.
Helps readers to understand how the process to gain valid consent might be approached postMontgomery.
Explains the difference between material and nonmaterial risks.

The switch from the standard of the reasonable professional, to that of the reasonable patient in cases where it is alleged that a health professional has not imparted sufficient information to allow the gaining of valid consent, has created anxiety and confusion within the dental profession. The ruling in Montgomery v Lanarkshire Health Board is relatively young; there have been insufficient subsequent cases to truly allow a deep exploration of the real changes that the case will bring to the way dentistry and other health activities are provided. One way that light may be shone onto the significance of Montgomery is to examine the development of the law in this area from Australia. Australia and the UK share a common history and while each legal system is independent from the other, they hold significant influence upon each other's destiny. This article seeks to shed light on the true relevance of Montgomery to dentistry in the UK through examination of the Australian position towards the gaining of valid consent which has enjoyed somewhat of a head-start in this area of the law.

\section{Opinion}

Since the determination in the case of Montgomery v Lanarkshire Health Board ${ }^{1}$ (hereafter referred to as Montgomery) the health professions in the United Kingdom have been forced to reconsider policies and procedures relating to shared decision-making. While the judgement of the Supreme Court of the UK is, upon first glances, thought to be a seismic shift in approach, it has served to somewhat align the positions relating to the duty to inform between the UK and Australia. In this article, the extent to which Montgomery really has disrupted the established view of consent will be examined. In Australia, the High Court rejected the accepted Bolam test ${ }^{2}$ of the reasonable practitioner with regard to failing to inform in the case of Rogers v Whitaker ${ }^{3}$ some 22 years before the UK Montgomery judgement in the Supreme Court. Prior to Montgomery, the

'Lecturer in Dental Ethics, Law and Professionalism, Faculty of Dentistry, University of Sydney, 2-6 Chalmers Street,

Surry Hills, NSW, 2010, Australia

Correspondence to: Alexander Holden

Email: alexander.holden@sydney.edu.au

Refereed Paper. Accepted 29 August 2017

DOI: 10.1038/sj.bdj.2018.1
Bolam standard accepted by the courts was applicable in both negligent treatment and failure to warn cases. Montgomery has not removed the application of Bolam to matters of negligent treatment, and only applies to claims based upon a failure to warn. The decision in Montgomery has moved the UK position closer to that of Canada given in Reibl v Hughes ${ }^{4}$ and the United States decision in Canterbury v Spence, ${ }^{5}$ although perhaps not to the extent that it has aligned to Australia. Since the ruling given in Rogers $\mathrm{v}$ Whitaker, Australian common law has further developed the switch from a paradigm of the 'reasonable practitioner' standard to one of the 'reasonable patient' in cases where there is alleged failure to inform of risks to treatment.

This article will seek to examine how this common law position has developed and how UK dental professionals might approach the consent process post-Montgomery. Any claim that the decision of the UK Supreme Court has changed healthcare practice monumentally would be an exaggeration. While in practice many may now be paying attention to the issue of consent with wider eyes, the regulatory infrastructure within medicine and dentistry has supported the idea of shared decisionmaking in a patient-centric manner for some time. The General Medical Council's guidance,
Consent: patients and doctors making decisions together, ${ }^{6}$ states that assumptions about the knowledge and understanding of patients about matters of consent should not be made and that if treatments have potentially serious adverse outcomes, patients must be informed of these. Similarly, the General Dental Council also supports this approach. Interestingly, the now superseded guidance, Principles of patient consent, stated; 'find out what your patients want to know as well as telling them what you think they need to know.7 This previous guidance embodies the spirit of Montgomery well and yet pre-dates the Montgomery decision by ten years. Despite this pre-existing guidance, it is possible to find confusion and a sense of exasperation within some of the literature dealing with the new stance of the common law for health professionals. D'Cruz and Kaney state:

'The requirement is that a dentist, in respect of consent, should tell the patient everything they want to know as well as everything the dentist thinks they might need to know. You might be forgiven for thinking that this has a mystic clairvoyant feel about it and you may not be far wrong.

While one suspects that the authors made this statement with their tongues firmly in cheek, there exists a large degree of congruence 
with this outlook within the profession at large. There is clearly a need for some development and elaboration of the new 'reasonable patient' standard for dental professionals to understand their obligations and how these are to be carried out. It is to explore the potential development of Montgomery in UK law and how the patient-centric consent standard should be considered that this article is written.

The now-overturned case of Sidaway $\mathrm{v}$ Board of Governors of the Bethlem Royal Hospital $^{9}$ reaffirmed the application of the Bolam principle in failure to warn cases in the UK at the time of its deciding. However, of note within the judgement was the opinion of Lord Scarman who stated:

'In my view the question whether or not the omission to warn constitutes a breach of the doctor's duty of care towards his patient is to be determined not exclusively by reference to the current state of responsible and competent professional opinion and practice at the time, though both are, of course, relevant considerations, but by the court's view as to whether the doctor in advising his patient gave the consideration which the law requires him to give to the right of the patient to make up her own mind in the light of the relevant information whether or not she will accept the treatment which he proposes. ${ }^{10}$

Lord Scarman held the minority dissenting view in Sidaway, often relegated to discussions within legal tomes and academia. However, that view was brought into the fore in the 1992 Australian High Court case of Rogers v Whitaker. In Sidaway, the risk of the injury that materialised was less than one percent. This was thought by Lord Bridge and Lord Templeman to be so low that reasonable medical opinion was justified in not disclosing the risk. In comparison, in Rogers v Whitaker, the risk of the plaintiff, Marie Whitaker, developing sympathetic opthalmia (whereby she became effectively blind in both eyes) resultant from an operation upon her right eye was 1 in 14,000. The High Court of Australia took the view in Rogers $\mathrm{v}$ Whitaker shared by Lord Scarman in Sidaway and rejected the Bolam principle. The overarching idea in both Rogers and Montgomery is that the amount of information given to patients is based upon material risk. The test of materiality given in the case of Montgomery is:

'whether, in the circumstances of the particular case, a reasonable person in the patient's position would be likely to attach significance to the risk, or the doctor is or should reasonably be aware that the particular patient would likely attach significance to it. ${ }^{31}$
As we have seen, this may be construed by some to place a burdensome duty upon practitioners where they are responsible for determining what matters to patients and what does not.

The finding in Montgomery could be interpreted as a negative development for health professionals; medical opinion in the courts being set aside in favour of the standard of a reasonable patient. Another way in which Montgomery could be interpreted is that all risks are material and therefore must be discussed with the patient, even those with such a low likelihood of occurrence (1:14,000 for example, as in Rogers $\mathrm{v}$ Whitaker). A rather exaggerated way in which the judgement has been interpreted (and indeed the way that expert commentary on the issue has been interpreted) is that rather than a paternalistic model of care, patients should have all options laid out before them and simply be allowed to choose that which suits them best. ${ }^{12}$ The rejection of paternalism in favour of an informative model ${ }^{13}$ of patient care is not appropriate. While paternalism has no place within healthcare, neither does the abandonment of patients by healthcare professionals abstaining from the decisionmaking process in the false interpretation that by stepping away, they are fulfilling their professional duty. Professional guidance does not support this attitude; guidance released by the Royal College of Surgeons ${ }^{14}$ following the Montgomery judgement details the consent process and how practitioners must adapt to the change in legislation so as to be compliant. While the material test in Montgomery would go so far as to instruct a clinician that they must give those risks that would be relevant to a particular patient, there is no guidance within the judgement of how a health professional might determine what risks might be relevant. This could take practitioners back to the strategy of simply giving all information in a situation where they are unsure of what risks might be material. The absence of a set formula takes the matter of duty away from a rigid framework whereby risks must be ranked in assessing their relevance; the exercise of relevance becomes instead far more targeted and individualised.

The case of Rosenberg v Percival ${ }^{15}$ in the Australian High Court affirmed the duty to warn of material risks that was given in Rogers $\mathrm{v}$ Whitaker. ${ }^{3}$ The nature of materiality was further developed by Justice Callinan when he stated that what had effectively been laid out was:

'both an objective and a subjective test, that is to say, a universal test for an hypothetical reasonable person in the patient's position, and a test to be applied to the particular patient, even if, perhaps, she or he is an unreasonable one. What this in practice may mean is that the more inquisitive, or demanding, or less or more sophisticated perhaps, or obsessive, or suspicious, or hypochondriacal the patient may be, the greater the need for identification of and elaboration upon the slightest risks because such a patient may be likely to attach significance to them. ${ }^{16}$

In his judgement, Justice Callinan references, as an example, that Marie Whitaker, the respondent in Rogers $\mathrm{v}$ Whitaker, ${ }^{3}$ was incessant in her questioning of Dr Rogers and mentioned on many occasions her concerns about developing blindness in her good eye. When such a patient presents who requests and desires a more comprehensive explanation of treatment, this should be given. This is in contrast to the respondent in Rosenberg $\mathrm{v}$ Percival; ${ }^{15}$ Dr Patricia Percival was a nurse of many years clinical experience who decided that she wanted to have her malocclusion treated. She saw Dr Rosenberg, an oral surgeon, and after several consultations went ahead with a bilateral sagittal split osteotomy. She was not warned of the risk of developing temporomandibular joint complications or nerve damage. She developed persistent post-operative pain that did not respond to physiotherapy or corrective surgery. While she was not warned of any risks of nerve or joint damage relating to the surgery, she equally did not ask about any. Dr Percival's claim failed on the basis that she failed to satisfy the High Court that had she been warned of the risk of nerve damage, she wouldn't have proceeded with treatment.

From the explanation of the objective and subjective aspects of the duty given by Justice Callinan, the Ipp Report, which reviewed the law of negligence, set out a proactive (objective) and reactive (subjective) duty to inform. It is these duties that are perhaps of most interest to UK health practitioners where there is uncertainty about the information-giving and shared decision-making process. The proactive duty is given to be:

'The proactive duty to inform requires the medical practitioner to take reasonable care to give the patient such information as the reasonable person in the patient's position would, in the circumstances, want to be given before making a decision whether or not to undergo treatment. ${ }^{17}$

The report goes on to state:

'A medical practitioner does not breach the 
Fig. 1 The Proactive and Reactive Duties

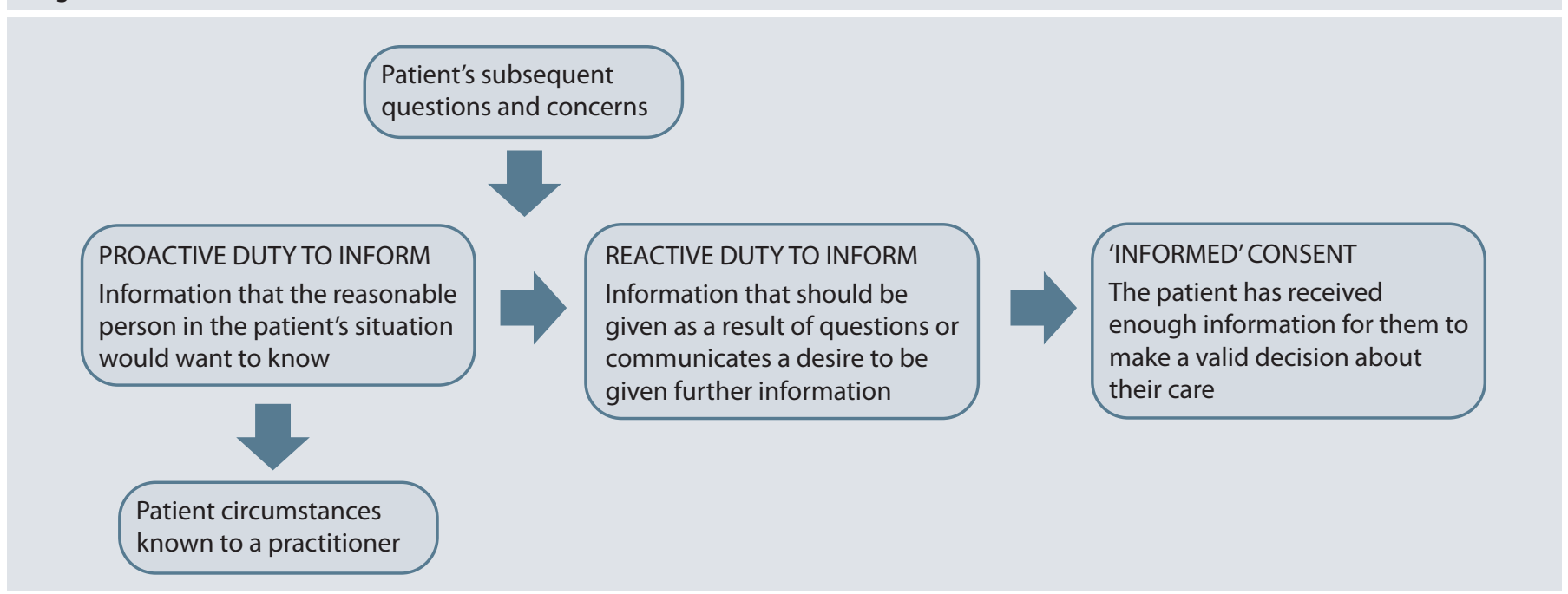

proactive duty to inform by reason only of a failure to give the patient information about a risk or other matter that would, in the circumstances, have been obvious to a reasonable person in the position of the patient, unless giving the information is required by statute. ${ }^{17}$

The reactive duty is given to be, 'The reactive duty to inform relates to information the practitioner must give when the particular patient asks for information, or otherwise communicates a desire to be given it. ${ }^{\prime 7}$ This practically means that at first instance, a health practitioner should give a reasonable amount of information, which, while the definition of this is given in a patient-focused manner, likely equates to a professionally accepted standard as well. It is then, upon the giving of this information that the wants and needs of the particular patient come into play, whereby further information is given relative to the material risks relevant to that individual elicited by their circumstances and response. This therefore extirpates any notion that postRogers or Montgomery, consent is simply a process of giving all information, regardless of relevance. It was explicitly stated in Rogers by Justice Gaudron, in reference to previous cases, that risks that are, 'far-fetched and fanciful' 18 and are not within the spirit of what is meant by a material risk. A 1:14,000 risk of developing sympathetic opthalmia which would lead to blindness in that eye is not fanciful to a patient who is already partially-sighted. The interaction between the proactive and reactive duties is described diagrammatically in Figure 1.

The idea that every small piece of possibly relevant information must be given to every patient before consent can be gained is dubious. In Rosenberg v Percival, ${ }^{15}$ Chief Justice Gleeson discussed the issue of the effect and remoteness of risk. It was stated that people face risks in daily life; the example given was that of a car accident on the way to the doctor's office. While a traffic accident may be a material risk in such a circumstance, most do not let such a worry prevent them from the normal carrying out of their daily lives. ${ }^{19}$ Montgomery has not been developed to create a doctrine of informed consent. Informed consent is not a strict concept that exists in either UK or Australian law. The idea of informed consent within healthcare practice is arrogant; the assumption that a patient cannot consent to treatment without having the level of information that health professionals have is flawed. In addition to this, it relies upon the assumption that the treating health professional has an absolute level of knowledge. Another postRogers case example that is of relevance to UK dental professionals is the Western Australian case of Mazurkiewicz v Scott. ${ }^{20}$ Mazurkiewicz attended to receive treatment from Dr Scott. Upon the administration of an inferior alveolar nerve block, the plaintiff reported a sharp pain. Subsequent to this appointment, Mazurkiewicz suffered from numbness of the left-side of his tongue as well as loss of sensation and some tasting ability of the same side. He sought damages against Dr Scott on the basis that he would not have had the procedure had this risk of nerve damage relating to the local anaesthetic been explained. Given the expert evidence given during the case, Judge Macknay QC took the risk of lingual nerve damage causing paraesthesia after one year post-operatively to be 1:12000. This is a higher risk of occurrence than the risk of sympathetic ophthalmia that materialised in Rogers. Despite this, the Court found in favour of Dr Scott. The reason for this decision hinges upon the reason for the procedure in the first place; Marie Whitaker, while blind in her right eye, was a woman in her fourth decade of life, who had thrived despite having been partially sighted since the age of nine. She did not depend upon the operation that Dr Rogers provided for her; it was entirely elective. Contrast this with the giving of local anaesthetic for a dental procedure and the reasons for the difference in outcome become illuminated. Justice Ipp stated in the case of Teik Huat Tai v Saxon:

'The need or otherwise of the procedure is highly relevant. One extreme could be treatment required to preserve the life of a patient. At the other extreme would be, for example, minor cosmetic surgery being considered for solely aesthetic reasons. The less urgent and critical the need for the procedure, the greater the need for advice as to the possible risks involved and as to possible different means of treating the problem. ${ }^{21}$

In the case of Rogers, Marie Whitaker didn't need to have the operation to preserve her wellbeing and throughout the process she was paranoid of somehow losing her sight in her good eye (as one might sympathise with someone who is partially sighted). If we imagine the case of Mazurkiewicz v Scott coming before a UK court post-Montgomery, one imagines that the outcome would likely be similar.

The UK case of Chester v Afshar, ${ }^{22}$ after the House of Lords decision was given, was quickly designated as being an erroneous decision and was all but forgotten about. And yet, despite this, Chester is yet to be definitively overturned and the arguments given in the case were used in Montgomery. In Chester, Ms Chester 
underwent surgery upon her back, carried out by Mr Afshar, a consultant neurosurgeon. She was not warned of the $1-2 \%$ risk of predictable complications. The finding in Chester is unusual when compared to Australian failure to warn cases. In Chester, Ms Chester did not deny that had she been informed of the material risks that she would not have had the surgery, in fact, it was very likely that even with the risks known, she was likely to have still proceeded with the operation. In the deciding of Chester, the House of Lords considered the Australian High Court decision in Chappel v Hart. ${ }^{23}$ In this case, the plaintiff stated that she would still have undergone the surgery if properly warned, but would have postponed the surgery and would have sought to have the treatment carried out by 'the most experienced' surgeon in the field. The High Court found the surgeon liable, despite the admission that the patient would have still had the surgery, albeit at another time. The common theme within Chester and Chappel is the finding of liability in the recognition of a violation of a patient's right to choose.

In Australia, a claim that, had a plaintiff known about a material risk, they would not have had the treatment is inadmissible in: New South Wales, ${ }^{24}$ Queensland, ${ }^{25}$ Tasmania ${ }^{26}$ and Western Australia. ${ }^{27}$ Taking the NSW legislation as an example, section 5D(3) of the Civil Liability Act states that, rather than relying upon the testimony of the plaintiff as to what he or she may have done, the matter is to be determined, 'subjectively in the light of all the relevant circumstances. ${ }^{28}$ The New South Wales Court of Appeal, in Elbourne v Gibbs, ${ }^{29}$ considered how causation could be established given the inadmissibility of a patient's testimony as per the Civil Liability Act. The following factors would be considered: 1) the remoteness of the risk; 2) the patient's desire for treatment; 3) previous and later procedures undertaken; 4) degree of faith in the medical practitioner; 5) the knowledge of the patient; and 6) the need for treatment and alternatives available. ${ }^{30,31}$ In the case of Rosenberg v Percival, ${ }^{15}$ the respondent, Dr Percival, ultimately failed to recover damages as she could not satisfy the court that had she known of the risks of orthognathic surgery, she would not have gone ahead. Chester is still difficult to see as a standardised method of determining causation in failure to warn cases. However, the principles of protecting patient autonomy that Chester extolls are not likely to fall from favour. Certainly, when considering that the approach to treatment cases and failure to inform cases has been differentiated, Chester seems to have new relevance and life. The Australian approach does not factor in the fact that in any event, the patient's autonomy has been breached. This could be argued to be in itself, grounds for enabling recovery of damages. This was the approach taken in the British case of Rees v Darlington Memorial Hospital Trust ${ }^{32}$ decided in the UK House of Lords. Here the court awarded compensation in acknowledgement of the breach to make informed and autonomous decisions about medical treatment that the pursuer had suffered. Lord Bingham stated that the reason for this was to, 'afford some measure of the recognition of the wrong done. ${ }^{33}$

\section{Conclusion}

One cannot hold with any certainty that the Australian legal path will be followed by the UK legal system, however, as the history of the development of the common law has shown, the Australian position is likely to be influential. The case of Montgomery was an important step in moving the law away from a focus on and deference to professional opinion. The UK decision of Bolitho ${ }^{34}$ made it clear that the courts were the final decisionmakers rather than the courts being chained to the opinions of experts. The development of the UK common law of consent subsequent to the Montgomery ruling will be interesting. Regardless of whether the law in the UK follows the Antipodean example, the principles of gaining consent as set out by Rosenberg $\mathrm{v}$ Percival and the Ipp Report would be well translated over to a post-Montgomery clinical environment; the objective and subjective duties of information giving transfer across to the UK well. The decision in Montgomery was undoubtedly a positive and overdue step to promoting patients' rights, moving the law to align with current bioethical thought. The decision of Montgomery may seem to some to be disruptive, but, as has been explored, the ratio decidendi of the case is not as radical as it might first seem. Patients should ultimately be the focus upon which a standard is based when deciding the amount of information that must be given. To place the onus upon patients in having to ask their attending clinician directed questions about a procedure they know little about would seem unfair, as if to punish those who do not share their dental professional's level of knowledge. The post-Montgomery environment of clinical practice is, in reality, very similar to that of pre-Montgomery. The real effect of Montgomery is that the position of the patient as being the focus of how much information should be given is simply formalised, rather than just implied.

1. Montgomery v Lanarkshire Health Board. 2015. UKSC 11 2. Bolam v Friern Hospital Management Committee. 1957. 1 WLR 582.

3. Rogers v Whitaker. 1992. HCA 58.

4. Reibl v Hughes. 1980. 2 SCR 880. 114 DLR (3d) 1.

5. Canterbury v Spence.1972. 464 F. 2 d 772.

6. General Medical Council. Consent: patients and doctors making decisions together. 2008. Available at http:// www.gmc-uk.org/guidance/ethical_guidance/consent guidance_index.asp (accessed June 2017).

7. General Dental Council. Principles of patient consent. 2005.

8. D'Cruz L, Kaney H. Consent - a new era begins. Br Dent J 2015; 219: 57-59.

9. Sidaway v Board of Governors of the Bethlem Royal Hospital. 1985. AC 871

10. Sidaway v Board of Governors of the Bethlem Royal Hospital. 1985. AC 871, 876 (Lord Scarman).

11. Montgomery v Lanarkshire Health Board. 2015. UKSC 11, 87 (Lord Kerr and Lord Reed).

12. Boseley S. Patients must understand options, says Royal College of Surgeons. The Guardian. 2016. Available at https://www.theguardian.com/education/2016/oct/27/ patients-must-understand-options-royal-collegesurgeons (accessed June 2016).

13. Emanuel $\mathrm{E}$, Emanuel L. Four Models of the physicianpatient relationship. JAMA 1992; 267: 2261-2266.

14. Royal College of Surgeons of England. Consent: Supported Decision-Making - a good practice guide. 2016. Available at https://www.rcseng.ac.uk/library-andpublications/college-publications/docs/consent-goodpractice-guide/ (accessed June 2017).

15. Rosenberg v Percival. 2001. HCA 18

6. Rosenberg v Percival. 2001. HCA 18, 210 (Callinan J).

17. Ipp D A, Cane P, Sheldon D, Macintosh I. Review of the Law of Negligence: Final Report, Commonwealth of Australia 2002. Available at https://static.treasury.gov.au/ uploads/sites/1/2017/06/R2002-001_Law_Neg_Final. pdf (accessed June 2017).

18. Rogers v Whitaker. 1992. HCA 58, 494 (Gaudron J).

19. Rosenberg v Percival. 2001. HCA 18, 14 (Gleeson J).

20. Mazurkiewicz v Scott. 1996. 16 SR (WA) 162.

21. Teik Huat Tai v Saxon. 1996. WASC No 23/95, 8 (Ipp J).

22. Chester v Afshar. 2004. 3 WLR 927.

23. Chappel v Hart. 1998. 195 CLR 232.

24. Civil Liability Act 2002 (NSW) s 5D(3)(b).

25. Civil Liability Act 2003 (QLD) s11(3)(b).

26. Civil Liability Act 2002 (TAS) s13 (3)(b).

27. Civil Liability Act 2002 (WA) $s 5 C(3)(b)$.

28. Civil Liability Act 2002 (NSW) s 5D(3)(a)

29. Elbourne v Gibbs. 2006. NSWCA 127.

30. Elbourne v Gibbs. 2006. NSWCA 127, 81 (Basten JA).

31. Addison T. Negligent Failure to inform: Developments in the law since Rogers v Whitaker. Torts Law J 2003; 10: 165-195.

32. Rees v Darlington Memorial Hospital Trust. 2004. 1 AC 309.

33. Rees v Darlington Memorial Hospital Trust. 2004. 1 AC 309, 317 (Bingham).

34. Bolitho v City \& Hackney Health Authority. 1997. 3 WLR 1151. 